\title{
Effectiveness of antipsychotic treatments in a nationwide cohort of patients in community care after first hospitalisation due to schizophrenia and schizoaffective disorder: observational follow-up study
}

Jari Tiihonen, Kristian Wahlbeck, Jouko Lönnqvist, Timo Klaukka, John P A Ioannidis, Jan Volavka, Jari Haukka

\begin{abstract}
Objective To study the association between prescribed antipsychotic drugs and outcome in schizophrenia or schizoaffective disorder in the community.

Design Prospective cohort study using national central registers.

Setting Community care in Finland.

Participants Nationwide cohort of 2230 consecutive adults hospitalised in Finland for the first time because of schizophrenia or schizoaffective disorder, January 1995 to December 2001.

Main outcome measures Rates of discontinuation of drugs (all causes), rates of rehospitalisation, and mortality associated with monotherapy with the 10 most commonly used antipsychotic drugs. Multivariate models and propensity score methods were used to adjust estimates of effectiveness.

Results Initial use of clozapine (adjusted relative risk 0.17, 95\% confidence interval 0.10 to 0.29$)$, perphenazine depot $(0.24$, 0.13 to 0.47$)$, and olanzapine $(0.35,0.18$ to 0.71$)$ were associated with the lowest rates of discontinuation for any reason when compared with oral haloperidol. During an average follow-up of 3.6 years, 4640 cases of rehospitalisation were recorded. Current use of perphenazine depot (0.32, 0.22 to 0.49$)$, olanzapine $(0.54,0.41$ to 0.71$)$, and clozapine $(0.64,0.48$ to 0.85$)$ were associated with the lowest risk of rehospitalisation. Use of haloperidol was associated with a poor outcome among women. Mortality was markedly raised in patients not taking antipsychotics (12.3, 6.0 to 24.1) and the risk of suicide was high (37.4, 5.1 to 276$)$.

Conclusions The effectiveness of first and second generation antipsychotics varies greatly in the community. Patients treated with perphenazine depot, clozapine, or olanzapine have a substantially lower risk of rehospitalisation or discontinuation (for any reason) of their initial treatment than do patients treated with haloperidol. Excess mortality is seen mostly in patients not using antipsychotic drugs.
\end{abstract}

\section{Introduction}

Treatment algorithms for schizophrenia are currently based on outcome data from randomised controlled trials. Most of these trials are of small sample size, and most patients who exhibit substance misuse, somatic disease, insufficient compliance, and suicidal or antisocial behaviour are excluded. ${ }^{1}$ It is therefore dif- ficult to extrapolate data from such trials to wider community settings. Most randomised controlled trials have a follow-up of a few months, but schizophrenia is a life long condition. ${ }^{1}$ Thus, it is not known how the choice of antipsychotic drug affects the long term outcome of patients with a first episode of schizophrenia. Large scale observational studies could provide insight into these important aspects. ${ }^{2}$

Several new second generation antipsychotic drugs have been used during the past two decades (such as risperidone, olanzapine, and clozapine), and some have proved more efficacious than first generation drugs. ${ }^{3}$ Second generation antipsychotics may be better tolerated and adherence to treatment may also be better, but this issue remains controversial. ${ }^{4-6}$ Cost effectiveness should also be considered, as new drugs are more expensive, and choosing the best antipsychotic agents is therefore not straightforward.

In Finland, the National Hospital Discharge Register can identify all patients treated in hospital since 1967 and the diagnostic validity of schizophrenia is good. ${ }^{78}$ Information on mortality and cause of death is recorded by Statistics Finland, and all reimbursed drug prescriptions are registered by the Social Insurance Institution of Finland, which covers all patients living in Finland. By linking these databases, we studied the relative effectiveness of the most frequently used antipsychotic drugs among patients in the community after their first admission to hospital for schizophrenia or schizoaffective disorder.

\section{Methods}

\section{Assessment of outcomes}

The outcome measures were mortality, discontinuation of drugs for any reason (death, hospitalisation, discontinuation, or switch to another antipsychotic drug), and rehospitalisation, a key indicator of relapse. In Finland, more than $90 \%$ of patients with schizophrenic psychosis are hospitalised, and non-elderly patients with schizophrenia are rarely hospitalised except during a relapse. ${ }^{7}$

\section{Study population and data}

We studied all people in Finland who were hospitalised because of a diagnosis of schizophrenia or schizoaffective disorder (international classification of diseases, 10th revision (ICD-10) F20, F25; corresponding to 295 in the Diagnostic and Statistical Manual of Mental Disorders, fourth edition (DSM-IV)) from 1 January 1995 to 31 December 2001 (the first hospital treatment period was considered as the index period); who had no 
previous discharge registered after hospitalisation due to schizophrenia-like psychosis (until 1995: ICD-9 295, DSM-IV 2962-2967; from 1996 to 2001: ICD-10 F20, F23.1, F23.2, F25, F30.1-F30.9); and who were 15-45 years old when the index hospitalisation began.

We obtained information on the study population by register linkage through personal identification codes used routinely in Finnish registers. We obtained data on the index hospitalisation from the discharge register. These data included admission and discharge dates and diagnostic codes. Patients were admitted to psychiatric hospitals in $89 \%$ of cases and to general hospitals in $11 \%$. We obtained dates and causes of death from Statistics Finland. Data on use of antipsychotic drugs came from a nationwide prescription register. This register indicates whether the patient has bought drugs from a pharmacy. For convenience, "drug use" refers to buying drugs from a pharmacy. In Finland, prescriptions of antipsychotic drugs for patients with schizophrenia or schizoaffective disorder are reimbursed and filed by the National Social Insurance Scheme. The available data contained details of purchase date and dose (the international standard daily defined dose). Drugs were classified according to the anatomic therapeutic chemical classification system (anatomic therapeutic chemical classification/ daily defined dose index 2006; www.whocc.no/atcddd/indexdatabase/). ${ }^{9}$

For all patients studied, we obtained data on sex, age at index hospitalisation, year of index hospitalisation, duration of index hospitalisation (a proxy for baseline severity of illness), duration of all subsequent hospitalisations, and use of antipsychotic drugs after index hospitalisation. We used drug purchasing data to calculate the duration of antipsychotic treatment. We determined the 10 most commonly used drugs (olanzapine, clozapine, risperidone, oral perphenazine, thioridazine, perphenazine depot, chlorprothixene, chlorpromazine, haloperidol, and levomepromazine) and assigned patients who took only one of these drugs to the respective group. We assigned patients who took several antipsychotic drugs or uncommon drugs (such as quetiapine, sertindole, and haloperidol depot injection) to a separate group (mixed or rare) and those who did not take drugs to another group. (In Finland, aripiprazole and ziprasidone were not available until December 2001 and quetiapine was not available until April 2000.) Oral haloperidol is the standard reference drug in clinical trials so we used patients who took this drug as the reference group. ${ }^{3}$

\section{Data analysis}

We analysed the relative effectiveness of the drugs in three different ways. In the analysis of "all cause discontinuation of the initial drug," we categorised patients according to the first drug used after their index hospital treatment (started within 30 days of discharge). Follow-up was continued until the drug was discontinued in community care for any reason (death, hospitalisation, discontinuation, or switch to another drug) or the end of the study period, whichever occurred first.

Rehospitalisation and death were attributed to the current (ongoing) antipsychotic drug. For example, if after the first hospitalisation a patient took drug A for one year, then took no drugs for one year, then drug B for two years, and finally drug C for three years, we counted the number of rehospitalisations during each of these four risk sets (A, no drug, B, and C). We calculated the incidence of rehospitalisation and death in the whole patient population (incidents per person months for each drug). To obtain crude relative risks, we then compared these incidence figures for all drugs with the incidence figures for haloperidol.

We accounted for the impact of attrition during follow-up by calculating the relative risk of rehospitalisation for "initiated treatment" (monotherapy with a new antipsychotic drug started any time during the seven year follow-up) for each drug. This analysis is analagous to intention to treat analyses used in randomised controlled trials. "Initiated treatment" included the period of current use of the drug plus the period during which the patient stopped taking the drug before starting a new regimen.

We divided each patient's follow-up into contiguous periods of 30 days and counted the number of out of hospital follow-up time periods and the number of rehospitalisations in each time period. We also determined drug usage during the 30 day periods. The 30 day periods were used as units for Poisson regression analysis. In the analyses of "current" and "initiated" use, patients hospitalised after the index period were not in the risk set during their hospital stay. ${ }^{10}$ We used Poisson regression to obtain crude estimates of the risk of discontinuation of the initially used drug for any reason and the risk of rehospitalisation with current use of each drug versus current use of haloperidol. We adjusted estimates for background variables such as age, sex, calendar year, duration of index hospital treatment, length of follow-up, and number of previous hospitalisations (a time dependent variable). Estimates were also adjusted for the propensity to start a specific

\begin{tabular}{|c|c|c|c|c|c|c|c|}
\hline & $\begin{array}{l}\text { No of } \\
\text { relapses }\end{array}$ & $\begin{array}{c}\text { Person } \\
\text { years }\end{array}$ & Incidence & $\begin{array}{l}\text { Crude } \\
\text { relative risk } \\
(95 \% \mathrm{Cl})\end{array}$ & $\begin{array}{l}\text { Adjusted } \\
\text { relative risk } \\
(95 \% \mathrm{Cl})\end{array}$ & $\begin{array}{l}\text { Fully adjusted } \\
\text { relative risk } \\
(95 \% \mathrm{Cl})\end{array}$ & \\
\hline Perphenazine depot & 53 & 187 & 0.28 & 0.41 (0.29 to 0.59$)$ & $0.45(0.32$ to 0.65$)$ & $0.32(0.22$ to 0.49$)$ & $\rightarrow$ \\
\hline Olanzapine & 329 & 822 & 0.40 & 0.59 (0.45 to 0.75$)$ & 0.55 (0.43 to 0.72$)$ & $0.54(0.41$ to 0.71$)$ & $\rightarrow$ \\
\hline Clozapine & 336 & 804 & 0.42 & $0.61(0.47$ to 0.79$)$ & $0.53(0.41$ to 0.69$)$ & 0.64 (0.48 to 0.85$)$ & $\rightarrow-$ \\
\hline Chlorprothixene & 79 & 146 & 0.54 & 0.79 (0.58 to 1.09$)$ & 0.83 (0.61 to 1.15$)$ & 0.64 (0.45 to 0.91) & $\longrightarrow$ \\
\hline Thioridazine & 115 & 201 & 0.57 & 0.84 (0.63 to 1.12$)$ & $0.82(0.61$ to 1.10$)$ & $0.70(0.51$ to 0.96$)$ & $\because$ \\
\hline Perphenazine oral & 155 & 327 & 0.47 & 0.69 (0.58 to 0.82$)$ & 0.78 (0.59 to 1.03$)$ & 0.85 (0.63 to 1.13$)$ & $\longrightarrow$ \\
\hline Risperidone & 343 & 651 & 0.53 & 0.77 (0.60 to 0.99$)$ & $0.80(0.62$ to 1.03$)$ & $0.89(0.69$ to 1.16$)$ & $\rightarrow$ \\
\hline Mixed or rare & 775 & 1229 & 0.63 & $0.92(0.73$ to 1.17$)$ & $0.85(0.67$ to 1.08$)$ & $1.00(0.78$ to 1.28$)$ & $\rightarrow$ \\
\hline Haloperidol oral & 73 & 107 & 0.68 & 1.00 & 1.00 & 1.00 & $=$ \\
\hline Chlorpromazine & 82 & 127 & 0.64 & 0.94 (0.69 to 1.29$)$ & 0.97 (0.71 to 1.33$)$ & $1.06(0.76$ to 1.47$)$ & $\longrightarrow$ \\
\hline Levomepromazine & 52 & 63 & 0.82 & 1.21 (0.84 to 1.73$)$ & 0.82 (0.58 to 1.18$)$ & 1.09 (0.76 to 1.57$)$ & $\longrightarrow$ \\
\hline \multirow[t]{2}{*}{ No antipsychotic drugs } & 2248 & 3362 & 0.67 & 0.98 (0.77 to 1.23$)$ & 1.01 (0.80 to 1.27$)$ & 1.16 (0.91 to 1.47$)$ & $\rightarrow$ \\
\hline & & & & & & 0 & 1.0 \\
\hline
\end{tabular}

Fig 1 Relative risk of rehospitalisation by treatment. Adjusted for sex, calendar year, age at onset of follow-up, number of previous relapses, duration of first hospitalisation, and length of follow-up by a multivariate regression model alone (adjusted column) and by multivariate regression and the propensity score method (fully adjusted column) 
Table 1 Relative risk (95\% confidence interval) of rehospitalisation (relapse) in a cohort of patients in community care after first hospitalisation due to schizophrenia and schizoaffective disorder

\begin{tabular}{|c|c|c|c|c|c|c|}
\hline Variable & No of patients & No of re-hospitalisations & Person years & $\begin{array}{l}\text { Incidence of } \\
\text { rehospitalisation }\end{array}$ & Univariate analysis & Multivariate analysis \\
\hline \multicolumn{7}{|l|}{ Sex } \\
\hline$\overline{M a l e}$ & 1383 & 2801 & 4949 & 0.57 & 1.00 & 1.00 \\
\hline Female & 847 & 1839 & 3078 & 0.60 & 1.06 (1.00 to 1.12$)$ & $1.02(0.97$ to 1.09$)$ \\
\hline \multicolumn{7}{|c|}{ Age at onset of follow-up } \\
\hline$<25$ & 587 & 1288 & 1971 & 0.65 & 1.00 & 1.00 \\
\hline $25-34$ & 939 & 1988 & 3403 & 0.58 & 0.89 (0.83 to 0.96$)$ & 0.87 (0.81 to 0.94$)$ \\
\hline $35-45$ & 704 & 1364 & 2653 & 0.51 & 0.79 (0.73 to 0.85$)$ & 0.81 (0.75 to 0.88$)$ \\
\hline \multicolumn{7}{|c|}{ Duration of index hospitalisation (days) } \\
\hline$<15$ & 421 & 928 & 1543 & 0.60 & 1.00 & 1.00 \\
\hline $15-29$ & 305 & 655 & 1204 & 0.54 & 0.90 (0.82 to 1.00$)$ & 1.01 (0.92 to 1.12$)$ \\
\hline $30-59$ & 536 & 901 & 1974 & 0.46 & 0.76 (0.69 to 0.83 ) & 0.93 (0.84 to 1.02 ) \\
\hline $60-89$ & 350 & 660 & 1258 & 0.52 & 0.87 (0.79 to 0.96$)$ & $1.05(0.95$ to 1.16$)$ \\
\hline$\geq 90$ & 618 & 1496 & 2047 & 0.73 & 1.21 (1.12 to 1.32$)$ & 1.44 (1.32 to 1.57$)$ \\
\hline \multicolumn{7}{|c|}{ No of previous relapses* } \\
\hline 0 & & 1427 & 4045 & 0.35 & 1.00 & 1.00 \\
\hline 1 & & 851 & 1847 & 0.46 & 1.31 (1.20 to 1.42$)$ & 1.85 (1.70 to 2.02 ) \\
\hline 2 & & 559 & 844 & 0.66 & 1.88 (1.70 to 2.07 ) & 3.40 (3.06 to 3.77$)$ \\
\hline 3 & & 385 & 493 & 0.78 & 2.21 (1.98 to 2.48 ) & 4.50 (4.00 to 5.07$)$ \\
\hline 4 & & 265 & 257 & 1.03 & 2.92 (2.56 to 3.33 ) & 6.36 (5.54 to 7.30$)$ \\
\hline$\geq 5$ & & 1153 & 539 & 2.14 & 6.06 (5.61 to 6.55$)$ & 13.88 (12.67 to 15.22$)$ \\
\hline
\end{tabular}

*No of patients not shown because during follow-up patients can be in several risk sets.

treatment other than haloperidol. ${ }^{11}{ }^{12}$ The following parameters were considered in building a propensity score: sex, age at start of follow-up, number of previous rehospitalisations, duration of the index hospitalisation, and length of follow-up. We estimated the conditional probability of receiving a certain drug using a multinomial log-linear model. ${ }^{13}$ From these probabilities, propensity scores were estimated for haloperidol (reference) and other treatments. We evaluated the consistency between the results obtained with multivariate regression adjustment alone and with both multivariate and propensity score adjustment. Mortality was modelled similarly. We carried out all analyses with $\mathrm{R}$ software. ${ }^{14} \mathrm{P}$ values are two tailed.

\section{Results}

\section{Study cohort}

The cohort consisted of 2230 patients (1383 men, 847 women). The median duration of the index hospitalisation was 51 days (interquartile range 22-96). The mean age of patients was 30.7 years (SD 7.6), and the average length of follow-up was 3.6 years.

Table 2 Median daily defined doses (interquartile range) of antipsychotic drugs in patients after discharge from index admission and over entire follow-up period

\begin{tabular}{lcccc} 
Drug & $\begin{array}{c}\text { No of patients } \\
\text { discharged } \\
\text { from index } \\
\text { admission }\end{array}$ & $\begin{array}{c}\text { Daily } \\
\text { defined } \\
\text { dose }(\mathbf{m g})\end{array}$ & Index admission & $\begin{array}{c}\text { Entire follow-up } \\
\text { period }\end{array}$ \\
\hline Risperidone & 240 & 5 & $0.5(0.2-1.0)$ & $1.0(0.9-1.0)$ \\
\hline Olanzapine & 197 & 10 & $1.0(0.2-1.4)$ & $1.2(1.0-1.5)$ \\
\hline Clozapine & 150 & 300 & $0.3(0.1-1.0)$ & $1.0(0.9-1.3)$ \\
\hline $\begin{array}{l}\text { Perphenazine } \\
\text { oral }\end{array}$ & 104 & 30 & $1.0(0.3-1.0)$ & $1.0(0.9-1.0)$ \\
$\begin{array}{l}\text { Thioridazine } \\
\text { Chlorpromazine }\end{array}$ & 62 & 300 & $1.0(0.3-1.0)$ & $1.0(0.9-1.0)$ \\
\hline \begin{tabular}{l} 
Chlorprothixene \\
\hline Haloperidol
\end{tabular} & 43 & 300 & $1.0(0.5-1.0)$ & $1.0(0.9-1.1)$ \\
\hline $\begin{array}{l}\text { Perphenazine } \\
\text { depot }\end{array}$ & 35 & 800 & $1.0(0.3-1.0)$ & $1.0(0.9-1.1)$ \\
\hline $\begin{array}{l}\text { Levomepromazine } \\
\text { Levom }\end{array}$ & 19 & 7 & $1.0(0.4-1.1)$ & $1.0(1.0-1.1)$ \\
\hline
\end{tabular}

In total, we recorded 4640 rehospitalisations and 84 deaths during follow-up. Young age, long duration of index treatment $(\geq 90$ days), and an increasing number of previous relapses were associated with increased risk of rehospitalisation $(\mathrm{P}<0.001$ for each variable; table 1 ). The most commonly used antipsychotic drug during the entire follow-up period (indicated by persons years; fig 1) was olanzapine, followed by clozapine, risperidone, oral perphenazine, thioridazine, perphenazine depot, chlorprothixene, chlorpromazine, haloperidol, and finally levomepromazine (fig 1). The most commonly used initial (first) drug was risperidone, followed by olanzapine, clozapine, oral perphenazine, thioridazine, chlorpromazine, chlorprothixene, haloperidol, perphenazine depot, and finally levomepromazine (table 2). Thus, risperidone and chlorpromazine were used more often, and olanzapine, clozapine, and perhenazine depot were used less often as the initial drug in community care when compared with their use during the entire follow-up period. Table 2 shows the daily doses of antipsychotic drugs after discharge from the index admission and over the entire follow-up period. We calculated the daily dose as described previously. ${ }^{15}$

\section{Relative effectiveness: discontinuation of initial treatment}

Table 3 shows the all cause risk of stopping initial treatment started within 30 days of discharge from the index hospitalisation. In total, $797(35.7 \%)$ patients took no antipsychotic drugs during this period. Clozapine (adjusted relative risk 0.17, 95\% confidence interval 0.10 to 0.29$)$, perphenazine depot $(0.24,0.13$ to 0.47$)$, and olanzapine $(0.35,0.18$ to 0.71$)$ had the lowest rate of discontinuation for any reason. Risperidone also had a significantly lower risk of all cause discontinuation compared with oral haloperidol $(0.49,0.33$ to 0.74$)$. When stratified by median dose of haloperidol ( $8 \mathrm{mg} /$ day) at discharge from index admission, the results for clozapine and perphenazine depot were essentially unchanged (table 3 ).

\section{Relative effectiveness: current use}

Significantly decreased crude risks of rehospitalisation were associated with current use of perphenazine depot $(-59 \%$ reduction in relative risk compared with haloperidol), olanzap- 
Table 3 Risk of all cause discontinuation (death, hospitalisation, discontinuation, or switch to another drug) of initial antipsychotic drug (started within 30 days of discharge after the hospital treatment period). Values are relative risk ( $95 \%$ confidence interval) unless otherwise indicated

\begin{tabular}{|c|c|c|c|c|c|c|c|c|c|}
\hline Drug & $\begin{array}{c}\text { Person } \\
\text { years }\end{array}$ & $\begin{array}{l}\text { Mean } \\
\text { age } \\
\text { (years) }\end{array}$ & $\begin{array}{l}\text { Length of first } \\
\text { hospitalisation } \\
\text { (days) }\end{array}$ & Discontinued $^{*}$ & Hospitalised $\dagger$ & $\begin{array}{l}\text { Incidence of all } \\
\text { cause } \\
\text { discontinuation } \\
\text { (/person years) }\end{array}$ & Crude analysis & Adjusted analysisł & $\begin{array}{l}\text { Adjusted analysis } \\
\text { (patients on low } \\
\text { dose haloperidol as } \\
\text { reference)§ }\end{array}$ \\
\hline Clozapine & 213 & 27.4 & 174.9 & 85 & 23 & 0.51 & 0.17 (0.12 to 0.24$)$ & 0.17 (0.10 to 0.29$)$ & 0.22 (0.07 to 0.71$)$ \\
\hline Perphenazine depot & 38 & 34.9 & 95.7 & 30 & 1 & 0.82 & 0.27 (0.17 to 0.44$)$ & 0.24 (0.13 to 0.47$)$ & $0.11(0.03$ to 0.41$)$ \\
\hline Olanzapine & 138 & 28.6 & 93.4 & 118 & 37 & 1.14 & 0.38 (0.26 to 0.54$)$ & 0.35 (0.18 to 0.71$)$ & 1.49 (0.44 to 6.77$)$ \\
\hline Risperidone & 129 & 30.7 & 61.8 & 176 & 38 & 1.66 & 0.55 (0.39 to 0.78$)$ & $0.49(0.33$ to 0.74$)$ & 0.98 (0.38 to 2.50$)$ \\
\hline Chlorpromazine & 25 & 31.0 & 65.0 & 48 & 12 & 2.41 & 0.80 (0.53 to 1.21$)$ & 0.56 (0.33 to 0.92$)$ & 0.50 (0.17 to 1.48$)$ \\
\hline Chlorprothixene & 18 & 30.0 & 80.4 & 36 & 4 & 2.25 & 0.74 (0.48 to 1.17$)$ & 0.73 (0.41 to 1.28$)$ & 1.36 (0.44 to 4.18$)$ \\
\hline Thioridazine & 30 & 32.1 & 52.3 & 50 & 10 & 2.03 & 0.67 (0.45 to 1.01$)$ & 0.75 (0.45 to 1.23$)$ & $1.51(0.50$ to 4.61$)$ \\
\hline Mixed or raref & 180 & 31.8 & 80.9 & 410 & 60 & 2.62 & 0.87 (0.62 to 1.22$)$ & 0.80 (0.56 to 1.14$)$ & 1.51 (0.68 to 3.35$)$ \\
\hline Perphenazine oral & 32 & 32.7 & 75.6 & 91 & 12 & 3.24 & 1.08 (0.74 to 1.57$)$ & 0.92 (0.58 to 1.46) & 2.54 (0.86 to 7.46$)$ \\
\hline Haloperidol oral & 12 & 31.5 & 53.8 & 32 & 5 & 3.01 & 1.00 & 1.00 & 1.00 \\
\hline Levomepromazine & 3 & 32.3 & 57.2 & 17 & 2 & 6.44 & 2.14 (1.23 to 3.72$)$ & 1.94 (1.03 to 3.69$)$ & 3.51 (0.44 to 4.18$)$ \\
\hline No antipsychotic drug & 2696 & 30.6 & 80.5 & $394^{* *}$ & 265 & - & - & - & - \\
\hline
\end{tabular}

Four patients not taking drugs died; no patients taking antipsychotic drugs died. End points of follow-up were all cause change in treatment status or the end of follow-up. ${ }^{*}$ No of patients who discontinued or switched their initial drug to another antipsychotic.

†No of patients who were hospitalised.

$\ddagger$ Adjusted for sex, calendar year, age at onset of follow-up, duration of first hospitalisation, and length of follow-up; also adjusted with propensity score method.

$\S$ Fully adjusted and stratified by median dose of haloperidol ( $8 \mathrm{mg} / \mathrm{day})$ at discharge from index admission. Patients with a low dose of haloperidol ( $\leq 8 \mathrm{mg} / \mathrm{day})$ form the reference group.

IPatients taking several antipsychotic drugs or uncommon drugs (such as quetiapine, sertindole, and haloperidol depot injection).

$* * 394$ patients not taking drugs changed their treatment status (started taking antipsychotic drugs).

ine $(-41 \%)$, clozapine $(-39 \%)$, oral perphenazine $(-31 \%)$, and risperidone (-23\%) (fig 1). In multivariate adjusted analyses and analyses that also considered the propensity score, the results for the first three drugs remained significant, with similar estimates of effect, but the results for oral perphenazine and risperidone were not significant. We found a significant interaction between sex and the effect of haloperidol on the risk of rehospitalisation (33 rehospitalisations in 71 person years in men; 40 rehospitalisations in 36 person years in women; $\mathrm{P}<0.001$ ), with a worse outcome among women using haloperidol. No other significant interactions were seen.

\section{Relative effectiveness: initiated use}

In the analyses of initiated use of drugs (fig 2), the lowest adjusted risks of rehospitalisation were associated with perphenazine depot $(-41 \%$ reduction in relative risk compared with haloperidol), clozapine $(-28 \%)$, and olanzapine $(-27 \%)$.

\section{Mortality}

In total, 84 patients died during follow-up. We found no significant differences between drugs. However, mortality was more than 10 times higher in patients not taking drugs than in patients currently taking antipsychotic drugs: 75 patients not taking drugs died (3362 person years) and nine patients taking drugs died (4664 person years) (adjusted relative risk 12.3, 6.0 to 24.1, corresponding to population attributable risk of $83 \%, 68 \%$ to $91 \%$ ). Twenty six suicides occurred in patients not taking drugs compared with one suicide in patients taking drugs (crude relative risk 36.1, 4.9-266; adjusted relative risk 37.4, 5.1 to 276 ). The corresponding figures for all unnatural deaths (suicides, violence, accidents) were 51 per 3362 person years and five per 4664 person years $(14.1,5.6-35.4)$ and for all natural deaths 24 per 3362 person years and four per 4664 person years $(8.3,2.9-$ 24.0).

\section{Discussion}

Linking national databases of mortality, drug purchasing, and hospital treatment enabled us to study the effectiveness of antipsychotic treatment in the wide community by using mortality, rehospitalisation rates, and discontinuation of drugs for any reason as the outcome measures. First and second generation antipsychotic drugs varied greatly in terms of treatment adherence and effectiveness in this patient population. Patients treated with perphenazine depot, clozapine, or olanzapine had a

\begin{tabular}{|c|c|c|c|c|c|c|c|c|}
\hline & $\begin{array}{l}\text { Current } \\
\text { relapses }\end{array}$ & $\begin{array}{l}\text { Person } \\
\text { years }\end{array}$ & $\begin{array}{c}\text { Relapses } \\
\text { in past } \\
\text { users }\end{array}$ & $\begin{array}{c}\text { Person } \\
\text { years }\end{array}$ & $\begin{array}{l}\text { Crude } \\
\text { relative risk } \\
(95 \% \mathrm{Cl})\end{array}$ & $\begin{array}{l}\text { Adjusted } \\
\text { relative risk } \\
(95 \% \mathrm{Cl})\end{array}$ & $\begin{array}{l}\text { Fully adjusted } \\
\text { relative risk } \\
(95 \% \text { CI })\end{array}$ & \\
\hline Perphenazine depot & 53 & 187 & 40 & 78 & $0.54(0.41$ to 0.70$)$ & $0.54(0.41$ to 0.70$)$ & 0.59 (0.47 to 0.73$)$ & $\rightarrow$ \\
\hline Clozapine & 336 & 804 & 203 & 238 & 0.79 (0.66 to 0.95$)$ & 0.64 (0.53 to 0.77$)$ & $0.72(0.59$ to 0.87$)$ & $\rightarrow$ \\
\hline Olanzapine & 329 & 822 & 286 & 345 & 0.81 (0.67 to 0.97$)$ & $0.67(0.56$ to 0.80$)$ & 0.73 (0.61 to 0.86$)$ & - \\
\hline Thioridazine & 115 & 201 & 66 & 789 & 0.73 (0.59 to 0.91$)$ & 0.75 (0.60 to 0.93$)$ & 0.75 (0.62 to 0.91$)$ & $\rightarrow$ \\
\hline Perphenazine oral & 155 & 327 & 150 & 391 & 0.66 (0.54 to 0.80$)$ & 0.77 (0.63 to 0.94$)$ & $0.75(0.63$ to 0.90$)$ & $\rightarrow$ \\
\hline Chlorpromazine & 82 & 127 & 73 & 159 & 0.83 (0.66 to 1.04$)$ & 0.89 (0.71 to 1.12$)$ & $0.82(0.66$ to 1.01$)$ & $\rightarrow$ \\
\hline Chlorprothixene & 79 & 146 & 86 & 151 & 0.85 (0.68 to 1.06$)$ & $0.90(0.72$ to 1.13$)$ & $0.85(0.69$ to 1.05$)$ & 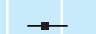 \\
\hline Mixed or rare & 775 & 1229 & 396 & 474 & 1.05 (0.89 to 1.25$)$ & 0.91 (0.76 to 1.08$)$ & $0.92(0.80$ to 1.08$)$ & $\rightarrow$ \\
\hline Haloperidol oral & 73 & 107 & 72 & 115 & 1.00 & 1.00 & 1.00 & . \\
\hline Levomepromazine & 52 & 63 & 89 & 78 & 1.53 (1.22 to 1.93$)$ & $1.01(0.80$ to 1.27$)$ & 1.07 (0.87 to 1.31$)$ & $\rightarrow$ \\
\hline \multirow[t]{2}{*}{ Risperidone } & 343 & 651 & 280 & 427 & 0.89 (0.74 to 1.06$)$ & $0.87(0.73$ to 1.05$)$ & $1.09(0.92$ to 1.28$)$ & $\rightarrow$ \\
\hline & & & & & & & 4 & 1.0 \\
\hline
\end{tabular}

Fig 2 Relative risk of rehospitalisation associated with the initiated use of each antipsychotic drug. Adjusted for sex, calendar year, age at onset of follow-up, number of previous relapses, duration of index hospitalisation, and length of follow-up by a multivariate regression model alone (adjusted column) and by multivariate regression and the propensity score method (fully adjusted column) 
lower risk of rehospitalisation or all cause discontinuation of their initial treatment than patients treated with haloperidol.

\section{Limitations and strengths of our study}

Observational studies may overestimate the size of treatment effects compared with randomised controlled trials. ${ }^{16-18}$ Naturalistic studies can provide data from unselected cohorts in the real world setting, but their main weakness is the potential for selection bias. The lower rate of discontinuation and risk of rehospitalisation associated with certain antipsychotic drugs could be attributable to patient selection (patients who received these drugs were more compliant and less severely ill than other patients). Our main findings were that perphenazine depot and clozapine had the lowest risk of all cause discontinuation and rehospitalisation. Since perphenazine depot is used mostly in patients with the worst adherence to drug treatment (those who do not comply with oral medication), and clozapine is used only in treatment resistant patients (the most severely ill), it is unlikely that selection bias could explain the better outcome associated with these drugs.

\section{Discontinuation of treatment}

Patients who started taking clozapine, perphenazine depot, or olanzapine within 30 days of their first hospitalisation had the lowest risk of stopping the initial treatment for any reason. In a recent meta-analysis of randomised trials comparing haloperidol with second generation antipsychotics, high haloperidol doses ( $>12 \mathrm{mg} /$ day) were associated with a poor outcome, but no substantial differences were seen between drugs at haloperidol doses $\leq 12 \mathrm{mg} /$ day. ${ }^{4}$ The median dose of haloperidol used in our study was $8 \mathrm{mg}$, well within the recommended optimal dose (6-12 mg/day)..$^{19}$ The relative risks of all cause discontinuation for clozapine and perphenazine depot were similar in an analysis stratified by median dose of haloperidol at discharge (patients taking low dose haloperidol were used as reference), but the confidence intervals were wider because of a smaller number of patients in the reference group.

\section{Rehospitalisation}

Initiated and current use of perphenazine depot, olanzapine, and clozapine were associated with the lowest risk of rehospitalisation, and patients who took these three drugs had a $27-68 \%$ lower risk of rehospitalisation than patients who took haloperidol. Depot injections of the first generation antipsychotic perphenazine were associated with the lowest risk of rehospitalisation. This drug is therefore cost effective, since second generation antipsychotics are much more expensive than first generation drugs. Our results are in line with a recent large randomised study that compared four second generation antipsychotics (not including clozapine) with first generation drugs and found that only olanzapine had a slightly better outcome than oral perphenazine. ${ }^{20}$

\section{Mortality}

The different drugs had no statistically significant effects on mortality, but the low number of deaths yielded low statistical power to detect such differences. Patients who currently took any antipsychotic drug had decreased mortality compared with the no treatment group. However, not using antipsychotic drugs may be a marker of other conditions that affect the risk of mortality. Nevertheless, efforts to reduce mortality among young schizophrenic patients (such as outreach programmes that contact patients or their family if prescriptions are not redeemed) should be targeted at this subpopulation.

Thanks to Aija Räsänen for excellent secretarial assistance.
Contributors: All authors helped conceive and design the study, analyse and interpret data, or draft and revise the article critically for important intellectual content. All authors approved the version to be published. JT is guarantor.

Funding: Annual EVO financing (special government subsidy) from Niuvanniemi Hospital, Kuopio, Finland.

Competing interests: None declared.

Ethical approval: No ethical committee approval needed for a register based study. Approval obtained from all institutions involved and from Ministry of Health and Social Welfare.

1 Thornley B, Adams C. Content and quality of 2000 controlled trials in schizophrenia over 50 years. BMJ 1998;317:1181-4.

Ioannidis JP, Haidich $\mathrm{AB}, \mathrm{Lau} \mathrm{J}$. Any casualties in the clash of randomised and observational evidence? BMI 2001;322:879-80.

3 Davis JM, Chen N, Glick ID. A meta-analysis of the efficacy of second-generation antipsychotics. Arch Gen Psychiatry 2003;60:553-64.

4 Geddes JR, Freemantle N, Harrison P, Bebbington PE. Atypical antispsychotics in the treatment of schizophrenia: systematic overview and meta-regression analysis. BMJ 2000;321:1371-6.

5 Geddes J. Prevention of relapse in schizophrenia. N Engl J Med 2002;346:56-8.

6 Leucht S, Wahlbeck K, Hamann J, Kissling W. New generation antipsychotics versus low-potency conventional antipsychotics: a systematic review and meta-analysis. Lancet 2003;361:1581-9.

7 Isohanni M, Makikyro T, Moring J, Rasanen P, Hakko H, Partanen U, et al. A comparison of clinical and research DSM-III-R diagnoses of schizophrenia in a Finnish national birth cohort. Clinical and research diagnoses of schizophrenia. Soc Psychiatry Psychiatr Epidemiol 1997;32:303-8.

8 Suvisaari JM, Haukka JK, Tanskanen AJ, Lönnqvist JK. Decline in the incidence of schizophrenia in Finnish cohorts born from 1954 to 1965. Arch Gen Psychiatry 1999;56:733-40

9 World Health Organization guidelines for ATC classification for DDD assignment. Oslo: WHO Collaboration Centre for Drug Statistics Methodology, Nordic Council on Medicines, 1999

10 Breslow NE, Day NE. Statistical methods in cancer research. II. The design and analysis of cohort studies. IARC Scientific Publications, No 82. Lyon: International Agency for Research on Cancer, 1987.

11 Rosenbaum P, Rubin DB. The central role of the propensity score in observational studies for causal effects. Biometrika 1983;70:41-55

12 Rubin DB. Estimating causal effects from large data sets using propensity scores. Ann Intern Med 1997;127:757-63.

13 Venebles WN, Ripley BD. Modern applied statistics with S. 4th ed. New York: Springer, 2002

$14 \mathrm{R}$ Development Core Team. $R$ : a language and environment for statistical computing. Vienna, Austria: R Foundation for Statistical Computing, 2004.

15 Mantel-Teeuwisse AK, Klungel OH, Verschuren WM, Porsius A, de Boer A. Comparison of different methods to estimate prevalence of drug use by using pharmacy records. J Clin Epidemiol 2001;54:1181-6.

16 Concato J, Shah N, Horwitz R. Randomized, controlled trials, observational studies, and the hierarchy of research designs. N Engl J Med 2000;342:1887-92.

17 Ioannidis JP, Haidich AB, Pappa M, Pantazis N, Kokori SI, Tektonidou MG, et al. Comparison of evidence of treatment effects in randomized and nonrandomized studies. parison of evidence of tre
JAMA 2001;286:821-30.

18 Benson K. Hartz AJ. A comparison of observational studies and randomized, controlled trials. N Engl J Med 2000;342:1878-86.

19 American Psychiatric Association. Practice guidelines for the treatment of patients with schizophrenia. Washington, DC: APA, 1997

\section{What is already known on this subject}

Guidelines for treating schizophrenia are mainly based on randomised controlled trials of selected patients with limited follow-up

How well these data can be applied to community settings and how the choice of antipsychotic drug affects long term outcome are unclear

\section{What this study adds}

The effectiveness of first and second generation antipsychotics varies greatly in a real world setting

Patients treated with perphenazine depot, clozapine, or olanzapine have a lower risk of rehospitalisation or all cause discontinuation of their initial treatment than patients treated with haloperidol

Excess mortality is seen mostly in patients not taking antipsychotic drugs 


\section{Research}

20 Lieberman JA, Stroup TS, McEvoy JP, Swartz MS, Rosenheck RA, Perkins DO, et al, Clinical Antipsychotic Trials of Intervention Effectiveness (CATIE) Investigators. Effectiveness of antipsychotic drugs in patients with chronic schizophrenia. N Engl J Med 2005;353:1209-23

(Accepted 14 April 2006)

doi $10.1136 / \mathrm{bmj} .38881 .382755 .2 \mathrm{~F}$

Department of Forensic Psychiatry, University of Kuopio, Niuvanniemi Hospital, FIN-70240 Kuopio, Finland

$\mathrm{J}$ Tiihonen professor and chairman

National Research and Development Centre for Welfare and Health (STAKES),

Helsinki, Finland

K Walhbeck research professor
Department of Mental Health and Alcohol Research, National Public Health Institute, Helsinki

J Lönnqvist research professor

J Haukka senior researcher

The Social Insurance Institution of Finland, Helsinki

T Klaukka research professor

Clinical Trials and Evidence-Based Medicine Unit, Department of Hygiene and Epidemiology, University of Ioannina School of Medicine, Ioannina, Greece

J P A Ioannidis professor

New York University, New York, USA

J Volavka professor emeritus

Correspondence to:J Tiihonen jari.tiihonen@niuva.fi 